\title{
Enhancement of numeric cognition in children with low achievement in mathematic after a non-instrumental musical training
}

\author{
Fabiana Silva Ribeiro ${ }^{\mathrm{a}}$, Flávia H. Santos ${ }^{\mathrm{a}, \mathrm{b}, *}$ \\ a Human Cognition Lab., School of Psychology, University of Minho, Campus de Gualtar, 4710-057 Braga, Portugal \\ b UNESP - São Paulo State University, Postgraduation Program in Developmental Psychology and Learning, Bauru Campus, Bauru, Brasil
}

\section{A R T I C L E I N F O}

\section{Article history:}

Received 14 July 2016

Received in revised form 7 November 2016

Accepted 17 November 2016

Available online 17 January 2017

Number of reviews completed is 1

\section{Keywords:}

Musical training

Numerical cognition

Dyscalculia

\begin{abstract}
A B S T R A C T
Studies suggest that musical training enhances spatial-temporal reasoning and leads to greater learning of mathematical concepts. The aim of this prospective study was to verify the efficacy of a Non-Instrumental Musical Training (NIMT) on the Numerical Cognition systems in children with low achievement in math. For this purpose, we examined, with a cluster analysis, whether children with low scores on Numerical Cognition would be grouped in the same cluster at pre and post-NIMT. Participants were primary school children divided into two groups according to their scores on an Arithmetic test. Results with a specialized battery of Numerical Cognition revealed improvements for Cluster 2 (children with low achievement in math) especially for number production capacity compared to normative data. Besides, the number of children with low scores in Numerical Cognition decreased at post-NIMT. These findings suggest that NIMT enhances Numerical Cognition and seems to be a useful tool for rehabilitation of children with low achievement in math.

(C) 2016 Elsevier Ltd. All rights reserved.
\end{abstract}

\section{What this paper adds?}

This study focused on a very important topic that has theoretical and practical implications for Mathematical Learning disabilities (i.e. whether there might be an effect of musical training on numerical cognition). Specifically, the authors aimed to show beneficial effects of a (non-instrumental) musical training on children's performance on numerical tasks. And results showed that children who exhibited deficits in numerical tasks at pre-test showed fewer deficits at post-test, precisely for Number Production following Musical training.

\section{Introduction}

Numerical Cognition, such as number-processing and calculation, is indispensable for daily life. According to McCloskey, Caramazza, and Basili (1985) number-processing can be divided into two components: number comprehension, which involves the understanding of numeric symbols, and number production that includes reading, writing, and counting numbers. By contrast, calculus is a system necessary to perform mathematical operations using symbols or words (addition, subtraction, multiplication, and division).

\footnotetext{
* Corresponding author.

E-mail addresses: id5157@alunos.uminho.pt, fabianaribeiropsi@gmail.com (F.S. Ribeiro), flaviahs@psi.uminho.pt (F.H. Santos).
} 
In terms of neurodevelopment, the five systems of Numerical Cognition gradually increase in a dynamic way: (i) the cardinal system, which is an innate system for concrete numerical representation and subitizing; (ii) the linguistic system, which associates a verbal code for numbers of objects or events; (iii) the Arabic system, which establishes a relationship between numbers and digits in Arabic form and supports the development of numeric symbolization; (iv) the visuospatial system, which aids the development of the mental number line along with formal education and the passage of time, and finally; (v) the ordinal system, which upon acquisition becomes the central system of numeric representation and mathematical thinking (Von Aster \& Shalev, 2007). On the other hand, the presence of numeracy deficits classified as Low Achievement in Math (LA) or Developmental Dyscalculia (DD) on the childhood may have deleterious impact on schooling and future professional careers.

DD is a disorder of arithmetical skills (F81.2) (ICD-10 - WHO, 2004) characterized by difficulties in performing basic operations such as addition, subtraction, multiplication and division. DD is not attributable to educational failures, intellectual disability or sensory problems (WHO, 2004). Primary DD can be understood as a heterogenic Numerical Cognition disorder whose effects can be observed at the behavioral, cognitive, and neuronal levels, whereas Secondary DD also generates numeric and arithmetic dysfunctions, which are related to non-numeric cognitive deficits or to comorbidity with disorders such as ADHD, dyslexia, and anxiety (Kaufmann et al., 2013). Moreover, it is important to observe substantial variations on criteria for DD before this categorization (Butterworth, 2010; Murphy, Mazzocco, Hanich, \& Early, 2007; Landerl, Bevan, \& Butterworth, 2004; Wilson \& Dehaene, 2007).

Despite the fact that DD occurs in approximately 5\% to 6.5\% of school-age children (Gross-Tsur, Manor, \& Shalev, 1996; Kaufmann \& von Aster, 2012), there are few studies focused on its diagnosis and rehabilitation in Brazil (see Kranz and Healy, 2013; for review), where it seems to have a slightly higher prevalence (Bastos, Cecato, Martins, Grecca, \& Pierini, 2016). European studies have investigated the effects of interventions on the persistence of DD in children of primary school (Kucian et al., 2011; Praet \& Desoete, 2014; Re, Pedron, Tressoldi, \& Lucangeli, 2014; for review see Cohen Kadosh, Dowker, Heine, Kaufmann, \& Kucian, 2013). These studies showed that children with DD may improve some Numerical Cognition abilities through adapted training (Praet \& Desoete, 2014; Re et al., 2014).

As for assessing the effects of rehabilitation in children with numeracy disorders, the study design usually compares a clinical group and a non-clinical group performing the procedure. For instance, Ashkenazi and Henik (2012) assessed nine children diagnosed with developmental dyscalculia and other nine age- and sex-matched controls with no disabilities. All of them participated in an attentional training which enhanced the performance in addition problems in both the DD and control groups. Kucian et al. (2011) developed a 5-week computer-based math training for children with DD aged 8-10 years and showed that the training improved spatial representation of the mental number line. Although these findings are promising, the effects of a virtual environment on the development of numeracy skills in children with DD depends on effective teaching strategies and the monitoring of teachers to use it as an individual approach (Moeller, Fischer, Nuerk, \& Cress, 2015).

There is evidence to suggest that music can increase higher brain functions required for mathematics, chess, science, and engineering (Davis, 2000). Schellenberg (2006) demonstrated associations between music lessons and academic performance such as mathematics, reading, and spelling in children aged 6-11 years. Moreover, Thornton (2013) compared test scores of 6.966 students in reading and math skills, and found significantly higher scores for students involved in musical classes (e.g. school band, choir, and orchestra) contrasting with students not engaged in music classes.

Willis (2016) found a significant connection between music education and student achievement in math, for those students who were provided music education at school. In fact, processing music and solving algebra problems trigger similar brain pathways in the prefrontal cortex and the parietal lobe (Schmithorst \& Holland, 2004). Moreover, music training could contribute to improve activations in encephalic areas such as planum temporale and the left dorso-lateral prefrontal cortex, areas which are considered important during mental arithmetics (Desmet et al., 2012).

Substantial evidence suggests that when children are enrolled in musical training, they exercise cortical neurons involved in music but they also refine circuits implicated in Numerical Cognition and spatial reasoning, which, consequently, develops the capacity to handle complex reasoning tasks (Wenger \& Wenger, 1990; Cheek \& Smith, 1998; Grandin, Shaw, \& Peterson, 1998). Importantly, spatial reasoning is subsidized in transforming and relating mental images in space and time, symmetries of the inherent cortical firing patterns used to compare physical and mental images, and natural temporal sequences of those inherent cortical patterns (Gentner, 2001). Correlational studies indicated that spatial ability is related to math ability throughout development since early elementary grades (Cheng \& Mix, 2014). Research also attested that quantities are represented in spatial formats (i.e., the mental number line and object files) beginning in early childhood and persisting into adulthood (Landerl, 2013).

The Miendlarzweska and Trost's (2013) review suggests that the improvement in math scores after music training could be due to near and far transfer effect skills. Indeed, it produces an increase in children's listening skills (as auditory discrimination) and verbal short-term memory (Forgeard, Winner, Norton, \& Schlaug, 2008; Moreno et al., 2011), executive functions (Hannon \& Trainor, 2007; Zuk, Benjamin, Kenyon, \& Gaab, 2014), and WM (Ribeiro \& Santos, 2012). Besides, musical training could be used as a tool to produce fast and permanent changes in cognitive abilities and has demonstrated an enhancement in visuospatial ability (Costa-Giomi, 1999; Rauscher et al., 1997; Ribeiro \& Santos, 2012; Ruscher \& Zupan, 2000; Rauscher \& Shaw, 1998; Yang, Lu, Gong, \& Yao, 2016).

Nutley, Darki, and Klingberg (2013) found music training to be related to greater performance on tests of reasoning, processing speed, WM, and numeracy ability, and there was a significant positive association between musical training and 
math performance at pre- and post-tests. There is a significant correspondence between musical training during childhood (4-6 years) and the later development of skills that involve the spatial visualization of information, such as geometry and mathematics resolution (Bilharz, Bruhn, \& Olson, 2000).

Considering the amount of practicing necessary, it seems that musical training boosts cognitive functions hastily. For instance, after four months of music training children performed better temporal-spatial tasks, i.e., activities that require both the use of spatial images and the temporal ordering of objects (Rauscher \& Zupan 2000). In another study Esteki (2013) assessed cognitive abilities before and after 16 sessions of music training in 13 girls ( $7-9$ years). Although details concerning the musical training method and math skills measured were not provided, the results showed increased scores in verbal, non-verbal, and general IQ, attention rate and numerical scores. Moreover, brain mapping showed that musical training improved verbal memory, which was associated with cortical reorganization in the left temporal region.

Regarding the technique, most studies used instrumental training (Costa-Giomi, 1999; Graziano, Peterson, \& Shaw, 1999; Rauscher \& Zupan, 2000), which involves repetition, feedback, and often gradual adjustment of difficulty (Klingberg, 2010), which will recruit, at the beginning of training, sensorimotor and auditory systems for automatization of responses (Herholz \& Zatorre, 2012). Moreover, it is founded in a traditional methodology of musical education in which contents are connected according to the level of difficulty based on an automated training on practicing a musical instrument (Camargo, 2007).

On the other hand, Non-instrumental musical training (NIMT) is reasoned as a multimodal training with an explicit methodology since it comprises teaching strategies to recognize musical properties, making children conscious of the material, not just repeating a sequence of auditory/motor movements on a particular instrument, such as the piano (Klingberg, 2010; Ribeiro \& Santos, 2015). As an outcome, NIMT promotes multi-sensory brain stimulation (Proverbio, Calbi, Manfredi, \& Zani, 2014), related to visual, auditory, and sensorimotor modalities causing an improvement of audio-visual integration due to the musical activities (Ribeiro \& Santos, 2012).

The NIMT is based on ecological resources such as singing, solfeggio, and rhythmic and melodic techniques (Ribeiro \& Santos, 2012; Ribeiro, 2013) with interpretative techniques. It is ecological in the sense that musical classes use methods and materials which approximate children to the real-world resources (Shadish, Cook, \& Campbell, 2002). Besides, children from developing countries such as Brazil usually have limited musical educational background, and/or no financial resources to buy musical instruments or to pay a private music teacher. At the same time, the government schools lack financial resources to acquire musical instruments. Moreover, NIMT may be an interesting option for rehabilitation since it stimulates cognitive functions in a ludic way (Ribeiro \& Santos, 2015), i.e., without tapping directly into the traditional context of math learning (Ribeiro, Tonoli, \& Santos, in Press). In addition, NIMT may be helpful to handle mathematical anxiety, which is commonly found in individuals with DD (Rubinsten \& Tannock, 2010).

Furthermore, the NIMT is built on active musical learning methodologies, such as Williams, Suzuki, Dalcroze Eurhythmics, and Suzuki methods, which combine music, movement and speech into lessons to make it analogous to a setting where children play (Goulart, 2000). Studies have claimed that melodic and rhythmic brain activations are dissociated, for example, the dorsal visual stream for melodic processing and the ventral visual stream for rhythmic activities (Bengtsson \& Ullén, 2006; Peretz \& Kolinsky, 1993; Warren, 1999). It is also important to point that almost all the studies cited above used instrumental musical training (Nutley et al., 2013; Rauscher \& Zupan, 2000) and some of them even specified the musical training used (Esteki, 2013).

The main purpose of this study was to determine the efficacy of a NIMT in children with deficits in numeracy skills. The authors hypothesized that there would be an increase in Numerical Cognition capacity after NIMT, especially in number comprehension and number production for children with low achievement in math and some of them will be grouped in a cluster with children without deficits in post-NIMT.

\section{Method}

\subsection{Participants and procedure}

Two-hundred-and-twenty-three Brazilian children, all primary students (112 boys, 8 year-olds) were screened for writing, arithmetic, and reading skills by the School Achievement Test (Stein 1994). They were enrolled in four public schools in the countryside of São Paulo State, Brazil. All participants were native Portuguese speakers and non-bilingual.

Twenty-six children that had no deficit or delay in any subtest of the School Achievement Test were included in the sample (EA - Expected Achievement in Math; 5 females). Twenty out 197 children (LA-Low Achievement in Math; 6 females) that had lower-than-average scores on the arithmetic subtest of the School Achievement Test when compared to normative data from second graders. These children with low math scores (cut-off $<9$ in the arithmetic subtest of School Achievement Test; Stein, 1994) were placed in the group 2. One of the established criteria for DD diagnosis is children to present results in arithmetic tests two grades lower than the expected school age, in the case of School Achievement test it was assumed by the cut- off $<9$ (Gross-Tsur et al., 1996). Moreover, DD diagnosis was confirmed by Zareki-R scores, in which children performed 1.5 Standard deviation below the mean age of normative data (Rotzer et al., 2009).

Groups were equivalents in abstract reasoning assessed by the Raven's Colored Progressive Matrices (CPM - Angelini, Alves, Custódio, Duarte, \& Duarte, 1999), executive function evaluated by the Wisconsin Card Sorting Test (WCST; Cunha et al., 2005), and in math-related anxiety investigated by Math Anxiety Scale (Carmo \& Figueiredo, 2005). The discrepancy 
Table 1

Means (and Standard Deviation) of Demographic Characteristics by Groups.

\begin{tabular}{llll}
\hline & EA $(\mathrm{n}=26)$ & LA $(\mathrm{n}=20)$ & $\mathrm{t}$ \\
\hline Age & $100.58(3.19)$ & $99.60(3.75)$ & \\
CPM & $79.81(11.87)$ & $62.95(20.45)$ & \\
School Achievement Test & & & \\
Writing & $22.81(2.76)$ & $21.95(2.14)$ & $3.51^{* * *}$ \\
Arithmetic & $10.08(2.40)$ & $61.00(2.54)$ & \\
Reading & $63.62(3.14)$ & $89.15(4.80)$ & $3.97^{* * *}$ \\
Total & $96.50(4.90)$ & $91.20(16.89)$ & $5.03^{* * *}$ \\
WCST & $93.23(14.39)$ & $42.60(21.13)$ & 0.44 \\
MathAS & $31.54(19.72)$ & -1.83 & \\
\hline
\end{tabular}

Note: EA - Expected Achievement in Math; LA- Low Achievement in Math; $\mathrm{n}=$ number of participants; CPM: Raven's Colored Progressive Matrices; WCST: Wisconsin Card Sorting Test; MathAS: Math Anxiety Scale. ${ }^{*} \mathrm{p}<0.05 ;{ }^{* *} \mathrm{P}<0.01$.

**** $\mathrm{P}<0.001$.

observed is that the LA presented statistically differences for verbal and visuospatial short-term memory and visuospatial working memory (AWMA, Alloway, 2007) (Table 1).

Socioeconomic status was assessed by the Brazilian Association of Marketing Research Institutes Scale that stratifies the socioeconomic status into five classes, from $\mathrm{A} /$ richest to $\mathrm{E} /$ poorest $(\mathrm{ABEP}, 2008$ ). In the present study socioeconomic status for both groups was classified as $\mathrm{C} /$ middle class, corresponding to $4-10$ minimum monthly wages. Exclusion criteria were based on parent and teacher reports prior NIMT. Exclusion criteria for both groups were: presence of emotional disturbances, motor difficulties, speech or hearing impairments, or diagnosis of a neurological or psychiatric disorder. Parents gave informed consent.

Selected participants were enrolled in government schools evaluated with 6.2 out of 10 points at Basic Education Development of Brazil, which corresponds to a good standard in education.

The study was approved by the ethics committee of UNESP, São Paulo State University.

After the screening phase participants were tested for Numerical Cognition using the Zareki-R. All children completed the pre-NIMT assessment before being assigned to the NIMT. A cluster analysis was performed with the results of the total of the scores of the Zareki-R to observe if the children would be clustered in the same group defined by school achievement test scores. The cluster analysis was justified as cluster subgroups that have similar response patterns can be useful in targeting appropriate treatment and studying typologies of diseases (Chaudhary \& Sharma, 2012). Both groups received 14 sessions of NIMT once a week, with each session being $60 \mathrm{~min}$ in duration, for the half of the subjects first 7 sessions were melodic activities and the others 7 sessions were rhythmic activities.

All neurocognitive assessments were conducted by a psychologist blind to the intervention status of the children and the NIMT was tutored by a music teacher who was unaware of the diagnosis of the children. In order to guarantee the fidelity of the implementation week meetings were made with the music teacher which in turn made reports about each lesson during the all period of the NIMT. Children were assessed in their own schools in a quiet room. Working memory and numerical cognition were assessed in a single session of 60 -min in average, with resting periods across the assessment, the order of subtests was not fixed and verbal tasks were alternated with nonverbal ones. Tests were the same as those used at pre- and post-test. The entire study (screening, NIMT and both pre- and post-tests - neurocognitive assessments) was carried out in the same schooling year.

\subsection{Non instrumental musical training}

The complete method was divided in melodic and rhythmic activities (detailed description below) just for technical reasons (Bengtsson \& Ullén, 2006; Peretz \& Kolinsky, 1993; Warren, 1999). Children were assigned in one of five mixed groups (4 groups with $\mathrm{N}=9$ and one group with $\mathrm{N}=10$ ). The selection of the mixed groups and the initial allocation onto rhythmic or melodic activities were random and balanced to each group. All topics were approached using practical activities rather than theoretical activities. There were seven sessions of each part of the method, and half of each group started by the melodic part methodology. The selection of the mixed groups and the initial part were assigned by pseudo-random assignment, since was respected children school periods, in which the training was performed in the opposite period. Groups were small to keep active participation and were formed based on schooling periods.

\subsubsection{Melodic activities}

1st Class: Discussed the notion of sound and silence, and provided the appreciation of sounds in different environments, such as the sounds of the class and outside the classroom.

2nd Class: Discriminated treble, midrange and bass sounds through the recognition of animal sounds and their differentiation.

3rd Class: Showed diverse musical instruments and timbre.

4th Class: Introduced the concept of intensity through songs and differentiations between utterances. 
5th Class: Exemplified the distinction between weak and strong sounds; stimulated the perception between intensities by listening to different musical styles.

6th Class: Presented representations of sounds through drawings and perception of musical styles.

7th Class: Introduced the concept of melody and harmony using different instruments and different notes.

\subsubsection{Rhythmic activities}

$1^{\text {rt }}$ Class: Presented rhythmic variations through pulse, body sounds and discrimination of musical progress.

2nd Class: Developed the perception between long and short sounds using musical games (with different pieces of paper that the children would interpret as long or short with sounds), body percussion and drawings.

3rd Class: Presented a description of the pulse and musical accent.

4th Class: Developed conceptions of pulse, rhythm and the use of different timbres and rhythms with own body.

5th Class: Showed properties of sounds such as duration and rhythmic association with movements.

6th Class: Stimulated the creation of rhythms and intensity.

7th Class: Discriminated the variations between binary, ternary and quaternary compasses.

\subsection{Measures}

Participants were screened for school achievements and evaluated in terms of intelligence quotient (IQ), socio-economic background. Further measures were administered to determine any systematic differences in these variables prior to the intervention:

Anamnesis (Santos, 2002): Consists of a set of questions to assess children general development in specific dimensions; social, educational, psychological and health. This was used as a screening measure for exclusion criteria, which were: presence of school failure, neurological, psychiatric or psychological disorders, and chronic use of psychoactive substances.

Brazilian Association of Marketing Research Institutes Scale (ABEP, 2008): A scale to assess the socioeconomic status of the child's family.

Raven's Colored Progressive Matrices (Angelini et al., 1999): A measure of nonverbal abstract reasoning.

School Achievement Test - (Stein, 1994): It is composed of three subtests: (1) Writing: In which the experimenter reads a maximum of 34 words and children are required to write them; (2) Reading: Is present a paper with 70 words in that the child is asked to read; and (3) Arithmetic: This subtest is composed by oral calculation and written calculation items. Each item presents a range of calculations in ascending order of difficulty, which are presented to children regardless of their school ages.

Wisconsin Card Sorting Test - WCST (Heaton et al., 2005): Assesses the ability to develop and maintain an appropriate strategy for problem solving by changing stimulus conditions order to reach a future target.

Math Anxiety Scale - MathAS (Carmo \& Figueiredo, 2005): 25 situation phrases that involve math and assess the level of anxiety in students.

Automated Working Memory Assessment - AWMA (Alloway, 2007): Twelve tests divided into the following four conceptual categories: verbal short-term memory- digit recall, word recall and non-word recall subtests; visuospatial short-term memory- dot matrix; mazes memory and block recall subtests; verbal working memory- listening recall, counting recall and backwards digits subtests; visuospatial working memory- Odd-one Out; Mister X and span spatial subtests. The description of each subtest is presented in Alloway and Passolunghi (2011), Ribeiro and Santos (2012).

\subsubsection{Numerical cognition}

Zareki-R (Von Aster \& Dellatolas, 2006) is an international specialized battery test that assesses the Numerical Cognition of school-age children. The total score is composed of the sum of the subtests, except Memory of Digits. The Zareki-R has 11 subtests specialized in Numerical Cognition: two of them assess Number Sense (counting dots and perceptive estimation subtests); Number Production (counting backwards, dictation of numbers and reading numbers subtests); Number Comprehension (oral comparison, written comparison and contextual estimation subtests); Calculation (mental calculation and problem solving scores) and mental number line (Positioning Numbers). Normative data for Brazilian children in each subtest and description of each subtest is presented in Santos et al. (2012).

\subsubsection{Post-NIMT self-report evaluation}

This instrument was designed especially for this study to assess if children could identify increasing with six topics related to School general learning, grades, memory, mood, attention, and finally about the importance of the musical training for them. Through six different questions: (1) Did you notice improvement in your school learning?; (2) Did you notice improvement in your grades?; (3) Did you notice changes in your memory?; (4) Did you notice modifications in your mood?; (5) Did you notice alterations in your attention?; And (6) Did the musical training mean something to you?. The parameter utilized to accounting in Fig. 4 was the children say yes or no, to each questions, in which yes responses were classified in terms of percentage of response for enhancement in the categories (Ribeiro, 2013). 
Table 2

Means (and Standard Deviation) scores obtained by groups on Zareki-R subtests and AWMA composites at Baseline.

\begin{tabular}{|c|c|c|c|c|}
\hline Tests & Cluster $1(\mathrm{n}=26)$ & Cluster $2(\mathrm{n}=20)$ & $\mathrm{t}$ & $\mathrm{d}$ \\
\hline \multicolumn{5}{|l|}{ Zareki-R } \\
\hline Counting Dots & $2.81(0.94)$ & $2.90(0.79)$ & -0.35 & 0.10 \\
\hline Counting Backwards & $2.77(1.24)$ & $1.35(1.04)$ & $4.12^{* * *}$ & $1.24^{\#}$ \\
\hline Dictation of Numbers & $13.42(3.01)$ & $7.80(3.35)$ & $5.98^{* * *}$ & $1.76^{\#}$ \\
\hline Mental Calculation & $24.73(6.90)$ & $8.75(6.22)$ & $8.12^{* * *}$ & $2.43^{\#}$ \\
\hline Reading Numbers & $14.42(2.23)$ & $10.05(3.73)$ & $4.94^{* * *}$ & $1.42^{\#}$ \\
\hline Positioning Numbers & $14.98(3.14)$ & $9.55(4.62)$ & $4.74^{* * *}$ & $1.37^{\#}$ \\
\hline Oral Comparison & $13.27(2.13)$ & $10.35(3.30)$ & $3.64^{* * *}$ & $1.05^{\#}$ \\
\hline Perceptive Estimation & $7.54(1.99)$ & $5.60(2.48)$ & $2.95^{* *}$ & $0.86^{\#}$ \\
\hline Contextual Estimation & $10.77(3.88)$ & $7.20(3.58)$ & $3.20^{* *}$ & $0.96^{\#}$ \\
\hline Problem Solving & $6.15(2.81)$ & $1.95(1.88)$ & $5.77^{* * *}$ & $1.76^{\#}$ \\
\hline Written Comparison & $19.08(1.29)$ & $15.40(4.82)$ & $3.73^{* * *}$ & $1.04^{\#}$ \\
\hline Memory of Digits & $24.69(5.09)$ & $22.21(5.25)$ & 4.03 & 0.08 \\
\hline Zareki-R Total & $129.98(14.14)$ & $80.90(12.13)$ & $12.40^{* * *}$ & $3.72^{\#}$ \\
\hline \multicolumn{5}{|l|}{ AWMA } \\
\hline Verbal Short Term Memory & $59.00(9.52)$ & $53.55(6.09)$ & $2.23^{*}$ & $0.68^{\dagger}$ \\
\hline Visuospatial Short Term Memory & $59.62(10.88)$ & $51.35(7.80)$ & $2.87^{* *}$ & $0.78^{\dagger}$ \\
\hline Verbal Working Memory & $34.77(8.02)$ & $31.45(6.89)$ & 1.48 & 0.44 \\
\hline Visuospatial Working Memory & $35.69(9.38)$ & $27.70(8.67)$ & $2.96^{* *}$ & $0.88^{\#}$ \\
\hline
\end{tabular}

Legend: Cluster 1: Expected Achievement in Math; Cluster 2: Low Achievement in Math; $\mathrm{n}=$ number of participants; Zareki-R: Neuropsychological Tests Battery of for Number Processing and Mental Calculation in children, Revised; AWMA: Automated Working Memory Assessment.

* $\mathrm{p}<0.05$.

** $\mathrm{P}<0.01$.

*** $\mathrm{P}<0.001$.

$\dagger \mathrm{d}>0.5$ respectively medium or large magnitude.

\# $\mathrm{d}>0.8$ respectively medium or large magnitude.

\section{Results}

The cluster analysis pre-NIMT indicated two groups: One presented average scores on the Zareki-R total score, while the other had the lowest scores on the Zareki-R, i.e., more than one standard devidation lower than expected for age. Therefore, the first group was designated as "Cluster 1", which had expected achievement in math scores $(n=26)$ and the second group as “'Cluster 2"', that had low achievement in math scores $(n=20)$, agreeing with the screening phase participants.

\subsection{Between-subject design at baseline}

In order to control multiple comparisons, the first analysis contemplated a MANOVA for independent variables (groups) and as dependent factor Zareki-R subtests which compose the total, and Wilk's Lambda $=0.21, \mathrm{~F}(11,34)=11,82, \mathrm{p}<0.001$, eta $=0.79$. As for achieving the post-hoc effect, independent samples $t$-test analyses were used, because it was the most appropriate test to compare the means for two independent groups. Results pre-NIMT showed differences between Cluster 1 and Cluster 2 for the following Zareki-R subtests: Counting Backwards, Dictation of Numbers, Mental Calculation, Reading Numbers, Positioning Numbers, Oral Comparison, Perceptive Estimation, Contextual Estimation, Problem Solving, and Written Comparison and also the Zareki-R wherein the performance of Cluster 1 group was higher than the children from Cluster 2. Means, standard deviations and comparison between groups by $t$-tests are summarized in Table 1 .

Once the children had significant differences in relation to intelligence scores, this fact could have determined the difference between groups in the Zareki-R subtests and total, for this reason, an ANCOVA having Raven's Colored Progressive Matrices scores as a covariate, was conducted and the group effect remained for Zareki-R subtests Wilk's Lambda $=0.26$, [F $(11,33)=8,37, \mathrm{p}<0.001$, eta $=0.74]$ and for the total $[\mathrm{F}(1,45)=108.29 ; \mathrm{p}<0.0001$, eta $=0.72]$.

The reliability indicated a Cronbach's alpha of 0.87 for pre-and post-NIMT for Zareki-R Total. Results were corroborated by effect sizes with large magnitudes.

Raw scores for dependent variables of each Zareki-R subtest (see Table 2) were converted to Z-scores based on normative data (Santos et al., 2012). These scores subsidized to create a control group, since the children were of the same age and cultural region (Fig. 1). Z-Scores confirmed the clustered group designed as DD group; the Zareki-R total mean for this group was 1.5 below the normative data (Santos et al., 2012), while EA group essentially had normal scores (Fig. 1).

Cluster 2 presented Zareki-R Total and counting backwards subtest scores according to clinical criteria, in other words, 1.5 SD below the mean expected for the age (Santos et al., 2012). Moreover, looking at each participant individually scores, 9 children had Zareki-R total score 1.5 SD below the mean expected for age (Santos et al., 2012), while others (11 children) presented deficits in three Zareki-R subtests (Rotzer et al., 2009), which means that children from cluster 2 had low achievement in math scores suggestive of DD (Kaufmann et al., 2013; Shalev, Manor, Auerbach, \& Gross-Tsur, 1998; Shalev, Manor, \& Gross-Tsur, 2005). Despite of difficulties presented by Cluster 1 in counting dots subtest, this group did not demonstrate deficits. 


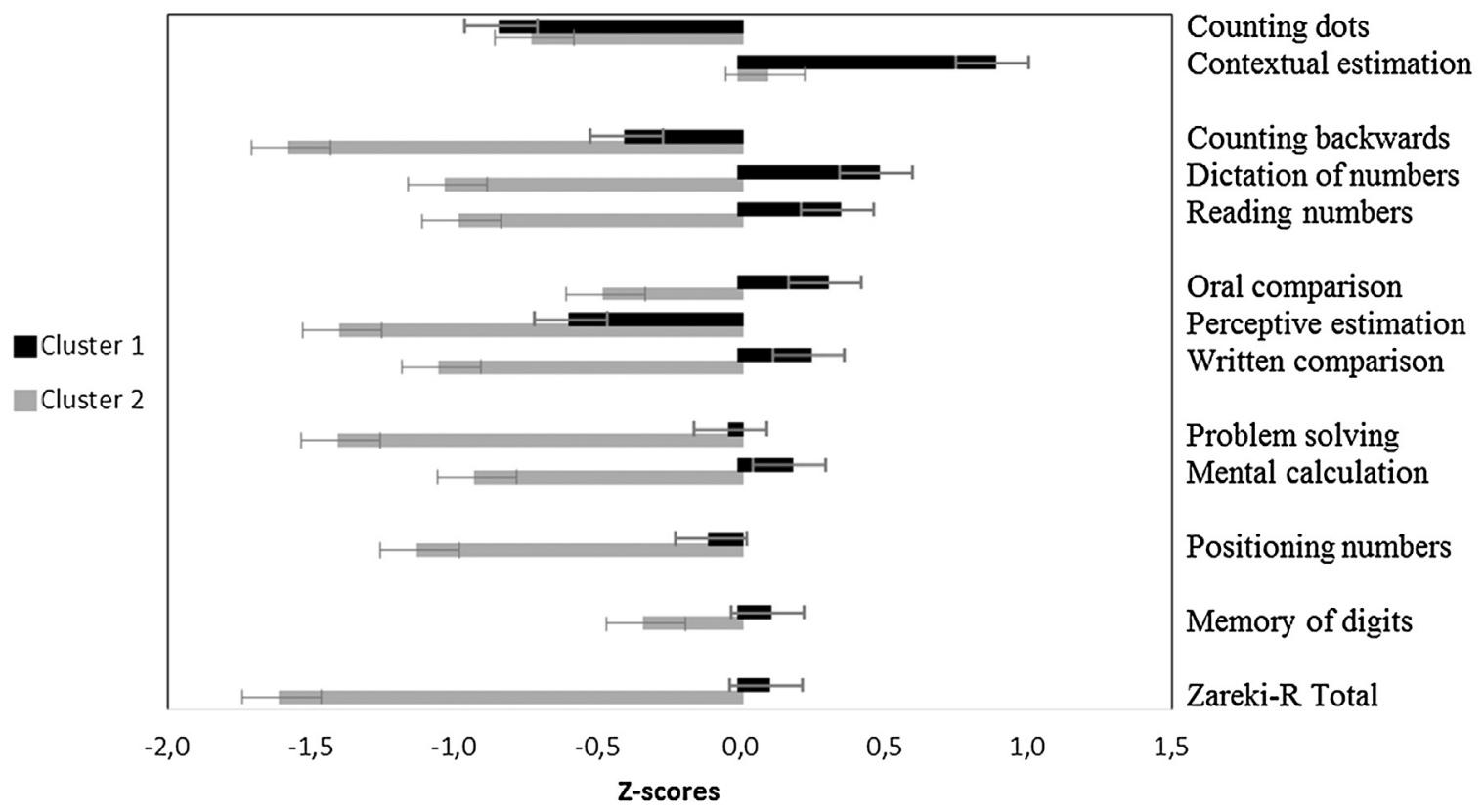

Fig. 1. Z-scores for subtests and Zareki-R Total score - mean and standard deviation- for cluster 1 and cluster 2 groups at pre-MT.

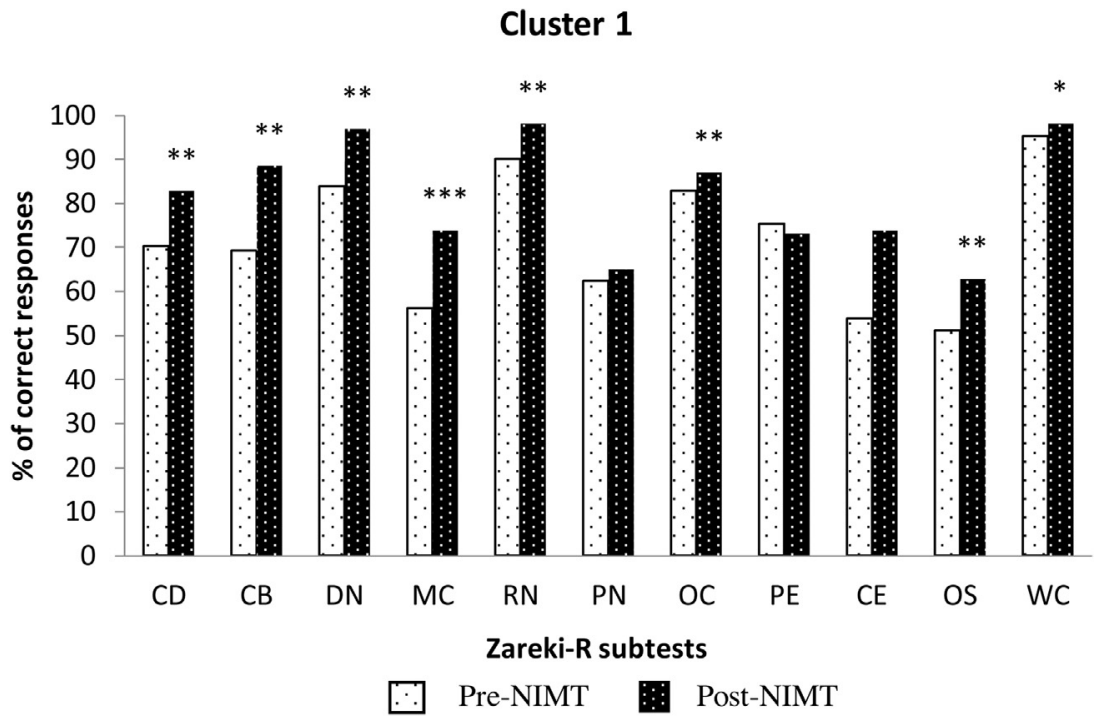

Fig. 2. Results of Cluster 1 group on subtests of Zareki $-\mathrm{R}(\mathrm{n}=26)$.

Note: $\left({ }^{*}\right) \mathrm{p}<0.05 ;\left({ }^{* *}\right) \mathrm{P}<0.01 ;\left({ }^{* * *}\right) \mathrm{P}<0.001$

Furthermore, cluster analysis was equivalent to school achievement test assessment at the screening phase.

\subsection{Within-subjects design (Pre-NIMT $\times$ post-NIMT)}

A paired t-test compared variables at pre- and post- NIMT. Analysis revealed a significant improvement in Cluster 1 group between pre- and post-NIMT for Counting dots, counting backwards, Dictation of numbers, Mental calculation, reading numbers, Contextual estimation, Problem Solving, Written comparison and Memory of digits (pre-test [M = 24.69; DP= 5.09] and post-test [M = 28.46; $\mathrm{DP}=5.13]$ ). In addition, Cluster 2 group increased their scores at post-MT for Counting dots, Dictation of numbers, Mental calculation, reading numbers, Positioning numbers, Contextual estimation and Problem solving. Results are shown in Figs. 2 and 3.

Legend: $\mathrm{CD}=$ Counting dots; $\mathrm{CB}=$ Counting backwards; $\mathrm{DN}=$ Dictation of numbers; $\mathrm{MC}=$ Mental calculation; $\mathrm{RN}=$ Reading numbers; $\mathrm{PN}=$ Positioning numbers; $\mathrm{OC}=$ Oral comparison; $\mathrm{PE}=$ Perceptive estimation; $\mathrm{CE}=$ Contextual estimation; $\mathrm{PS}=$ Problem solving; $\mathrm{WC}=$ Written comparison . 


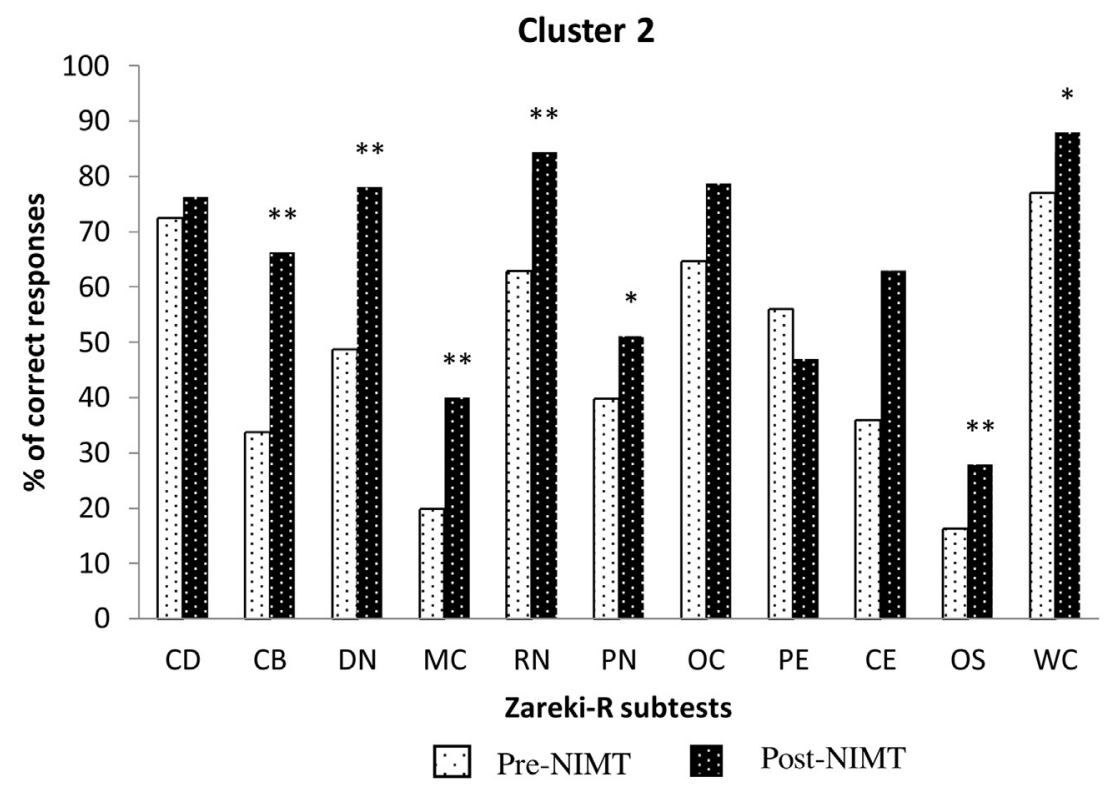

Fig. 3. Results of Cluster 2 group on subtests of Zareki-R $(n=20)$.

Note: $\left.\left({ }^{*}\right) \mathrm{p}<0.05 ;{ }^{* *}\right) \mathrm{P}<0.001$;

Legend: $\mathrm{CD}=$ Counting dots; $\mathrm{CB}=$ Counting backwards; $\mathrm{DN}=$ Dictation of numbers; $\mathrm{MC}=$ Mental calculation; $\mathrm{RN}=$ Reading numbers; $\mathrm{PN}=$ Positioning numbers; $\mathrm{OC}=$ Oral comparison; $\mathrm{PE}=$ Perceptive estimation; $\mathrm{CE}=$ Contextual estimation; $\mathrm{PS}=$ Problem solving; $\mathrm{WC}=$ Written comparison.

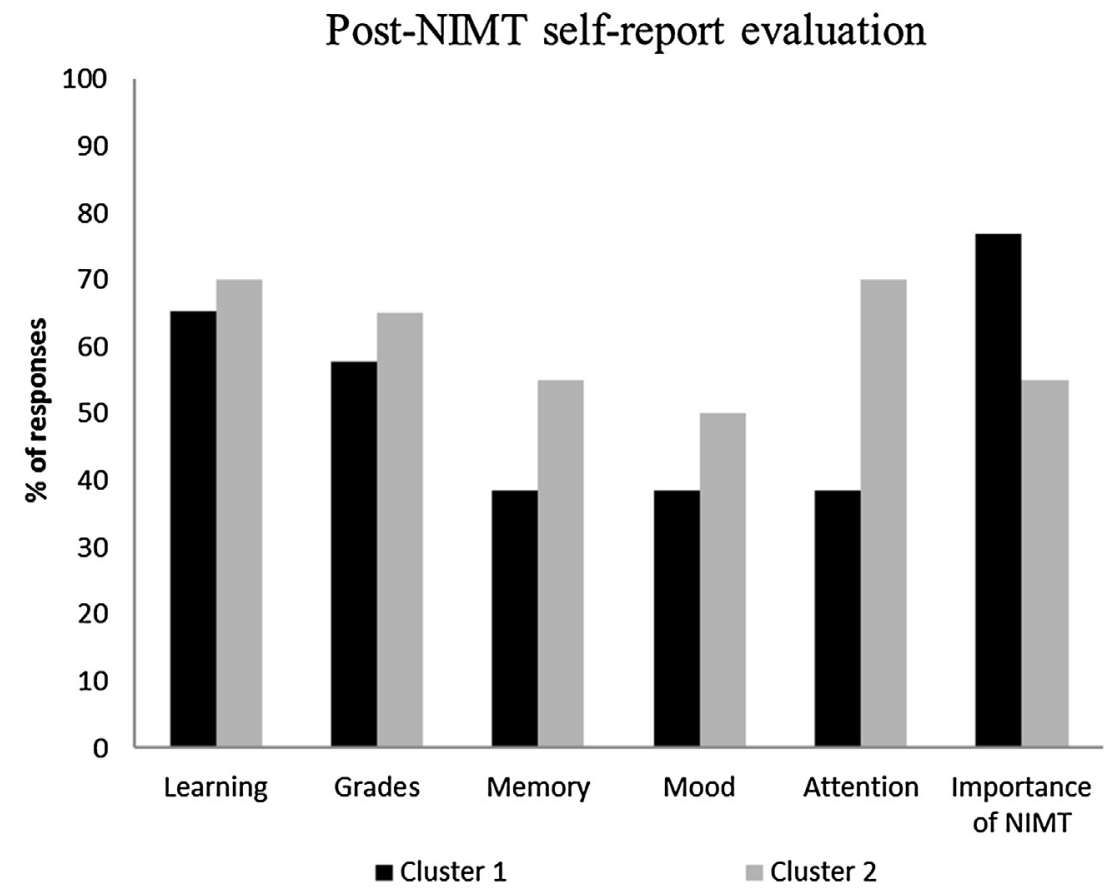

Fig. 4. Response percentage - for cluster 1 and cluster 2 groups for Post-NIMT self-report evaluation.

Moreover, non-significant differences were found using Mann-Whitney $U$ test between clusters in Post-NIMT self-report evaluation.

A second cluster analysis was carried out with the results of Zareki-R score after the end of the NIMT aiming to observe if children would still be grouped in the same cluster in post-NIMT, as in pre-NIMT. The analysis showed that 8 participants initially grouped in Cluster 2 group $(n=12)$, were grouped in Cluster 1 at post-NIMT $(n=34)$ and observing normative data neither Cluster 1 or Cluster 2 mean scores presented clinical criteria of DD (Santos et al., 2012; Rotzer et al., 2009). Fig. 4 shows the Z-scores for subtests and Zareki-R total for Clusters 1 and 2 at post-NIMT. 


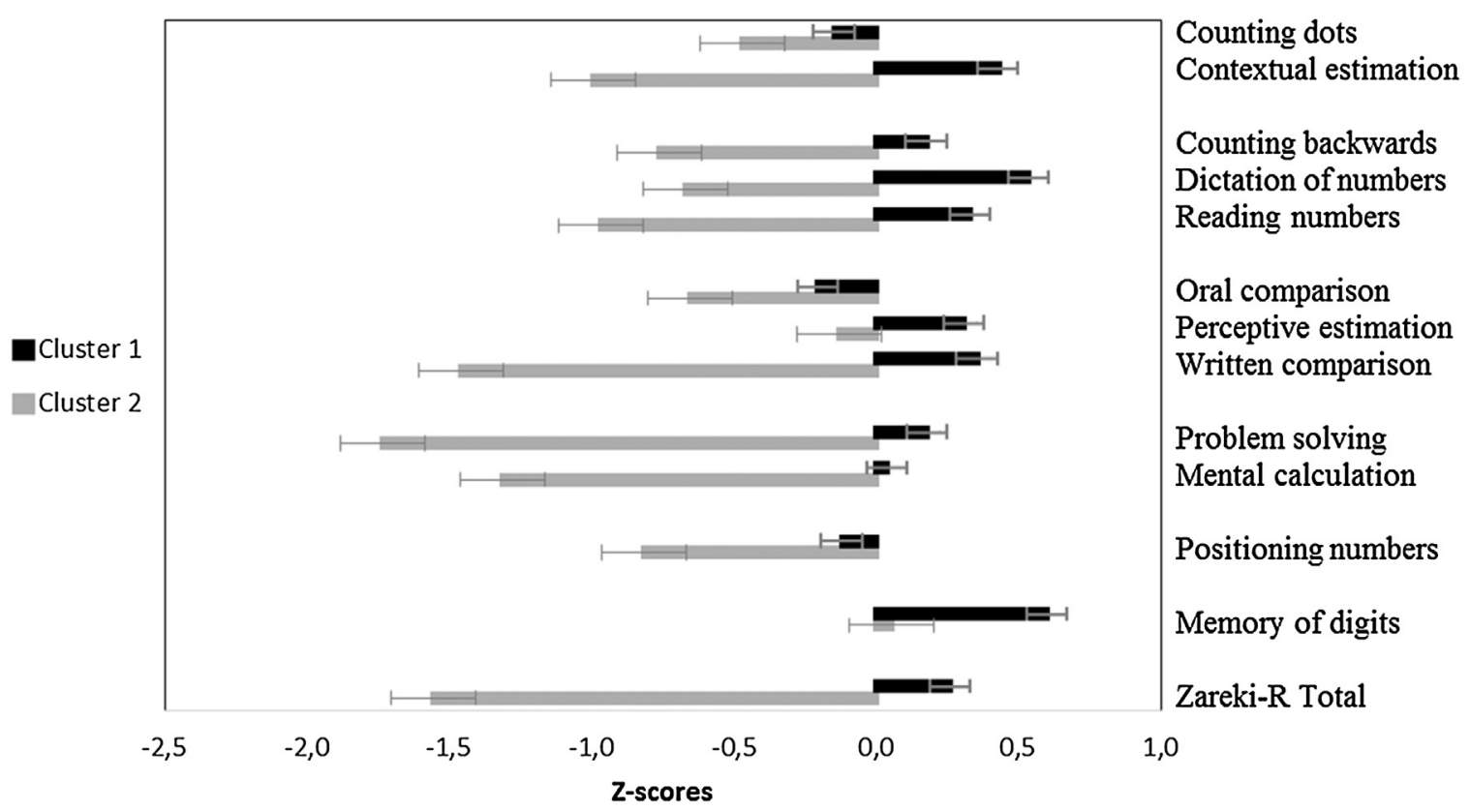

Fig. 5. Z-scores for subtests and Zareki-R Total score - mean and standard deviation- for cluster 1 and cluster 2 groups at Post-NIMT.

Table 3

Performance of child diagnosed with DD in Intelligence, Executive function, math anxiety, and School Achievement Test.

\begin{tabular}{llll}
\hline & Observed & Mean Expected & Classification \\
\hline CPM & 30 & $26-74$ & Average \\
WCST & 94 & $85-100$ & Average \\
MathAS & 0 & $0-24$ & No-symptoms \\
School Achievement Test & & & Average \\
Writing & 20 & $20-26$ & Impaired \\
Arithmetic & 4 & $10-13$ & Average \\
Reading & 61 & $58-66$ & Impaired \\
Total & 85 & $87-105$ & \\
\hline
\end{tabular}

Legend: CPM: Raven's Colored Progressive Matrices; WCST: Wisconsin Card Sorting Test; MathAS: Math Anxiety Scale.

Note: Averaged: in the range of mean expected; Impaired: Below the mean expected.

Observing individual results of each child at post-NIMT of Clusters 1 and 2, only 7 children in Cluster 2 continued to meet diagnostic criteria for DD, with the Zareki-R total score being below the mean expected for the age (Santos et al., 2012), outcomes are shown in Fig. 5. To illustrate individual results a case study was inserted (see Box 1).

\subsection{Case study}

In order to illustrate musical training effect in individuals, we selected a single case of a child that presented the worse scores in Zareki-R subtests before the intervention. R.L.is an eight-year-old boy enrolled in the 2nd school year of primary school. The anamnesis interview was made with the mother, who reported that pregnancy and birth were uneventful, as the psychomotor development. According to maternal reports, the child attended kindergarten and always presented difficulties in the discipline of mathematics. The family socioeconomic status corresponded to C1-monthly value 1.541 BRL ( $~ 684.89$ USD) (Table 3).

\subsubsection{Pre- NIMT}

R. L. obtained lower scores for arithmetic subtest and the total score compared to the expected mean. As for the subtests of Zareki-R, two of them presented mild impairment (counting dots and oral comparison), three subtests were classified as moderate impairment (counting backwards, dictations of numbers, and contextual estimation), five subtests and also the Zareki-R total had severe classification (mental calculation, reading numbers, positioning numbers, problem solving, and written comparison). The memory of Digits was the only subtest with averaged scores. It suggests a phenotype of Primary DD (Mazzocco \& Räsänen, 2013). 


\subsubsection{Post-NIMT}

At the end of the NIMT the child showed an improvement in six subtests, in which one subtest was classified as mild (Oral Comparison), others that were classified as moderate (Dictation of Numbers and Contextual Estimation), three subtests which had severe classification (Reading Numbers, Problem Solving, and Written Comparison). The two subtests that kept under severe impairment compared to the pre-NIMT were Mental Calculation and Positioning Numbers, corroborating with Budgen (2014) regarding persistent deficits in core skills. In congruence with Numerical Cognition improvements in scores, R.L. reported in the Post-NIMT Self-report evaluation yes for all questions, showing that the child could be able to notice beneficial changes in his cognitive, emotional and academic performances.

\section{Discussion}

The aim of the present study was to observe the effects of NIMT in children with low achievement in math, as a remedial strategy to enhance Numerical Cognition systems. For this purpose, a prospective study was carried out comparing pre- and a post-NIMT, in which children were assessed after 14 sessions of NIMT. The main finding was an enhancement of Number Production after the NIMT.

Initially, is important to point out that the children of the present study did not accomplish any other regular activity during the NIMT period, except schooling classes. Because our design did not have untrained group, we contrasted the present sample with children of the normative study of Zareki-R, which were from the same scholar background (for more information, Santos et al., 2012). Despite the observed statistical difference for intelligence between EA (Expected Achievement in Math children) and LA (Low Achievement in Math Children), covariance analyses revealed that performance in Numerical Cognition systems were not influenced by intelligence. In addition, none of the participants in this study had clinical deficits in executive function, intelligence, reading skills, math anxiety, or inadequate schooling opportunities, in other words, both groups presented averaged scores when compared to normative data.

Results of the between- design analysis revealed that only Cluster 2 (Low achievement in math children) was below the expected age scores for the following Zareki-R subtests: counting backwards, dictation of numbers, positioning numbers, contextual estimation, written comparison, and mental calculation (Santos et al., 2012), and according to Zareki-R established criteria for DD diagnosis (Rotzer et al., 2009; WHO, 1994). Deficits in these subtests indicate impairments in the understanding of numerical symbols and its production, which can justify losses in calculation (Butterworth, 2010; Landerl et al., 2004; Von Aster \& Shalev, 2007; Wilson \& Dehaene, 2007). It also confirms that the schooling achievement test is suitable for screening of numeracy deficits as focused on calculation, although a specific battery of Numerical Cognition is more suitable for the diagnosis of DD, since it likewise includes number processing skills (Santos et al., 2012; Silva \& Santos, 2011).

Based on Von Aster and Shalev (2007) model, it can be suggested that these deficits are observable from the linguistic step and Cluster 2 could be designated as a DD group. However, a careful diagnosis requires a longitudinal perspective (Mazzocco \& Räsänen, 2013) as demonstrated in this study. It is important to point out that the consensus recommendation for definition and diagnosis of DD emerged only three years ago (Kaufmann et al., 2013). Consequently, there are substantial number of studies with arbitrary diagnostic criteria for DD (Kaufmann \& von Aster, 2012) leading to individual differences (Butterworth, 2010; Murphy et al., 2007), which makes comparison with previous studies extremely difficult.

Besides, children in the Cluster 2 also showed inferior scores on visuospatial and verbal short-term memory and visuospatial WM (Silva \& Santos, 2012). It has previously been established that such impairment in this function has lead to difficulties in following instructions (Schuchardt, Kunze, Grube, \& Hasselhorn, 2006) and in mental representation (Alloway, 2006). This finding could help to reclassify them as Secondary DD since numerical deficits were associated with non-numerical cognitive ones.

After NIMT, an intra-group comparison revealed that both groups showed significant differences from pre-NIMT on the following Zareki-R subtests: counting backwards, dictation of number, mental calculation, reading numbers contextual estimation, and problem solving. However, only the Cluster 2 (Low Achievement in math) group showed increases in scores for positioning numbers, which is related to the mental number line (Kucian et al., 2011) and is connected to the spatial representation of number magnitude corroborating with previous studies that showed that music can develop spatial abilities (Rauscher \& Zupan, 2000; Rauscher \& Shaw, 1998). It is also relevant the fact that only the Cluster 1 (Expected Achievement in Math) showed an increase in scores for counting dots and written comparison subtests, which are linked to number production and WM. NIMT effects might be dissimilar between groups because children with low scores in Numerical Cognition can develop abilities in a different way compared to children with typical mathematic development (Landerl, 2013). Apart from that, this group-selective increase on scores makes a learning effect doubtful, if this was the case, all subtests would have grown equally for both clusters. In support of this argument, there was a good internal consistency, which would be lower in case of learning effects (Cronbrach, 1951). Data were analysed through the Z-score based on a normative score for Zareki-R (Santos et al., 2012). Furthermore, marginal significant results of self-report Post-NIMT indicated that children with low achievement scores were aware of their increases in math, corroborating with statistical results.

Another interesting finding from the present research is that the number of children grouped in Cluster $2(n=12)$, decreased after NIMT in that only 7 children remained with scores consistent with the diagnosis of DD. Two possible explanations must be considered for these results. Firstly, NIMT seems to be able to modify brain functioning in a short period of the time in children diagnosed with DD (Ribeiro, 2013; Ribeiro et al., 2016 in press). For instance, the child with lowest math scores at pre-NIMT that we selected from the cohort displayed, after NIMT, enhanced math scores related to number 
Table 4

Results of performance on Zareki-R by a child diagnosed with DD.

\begin{tabular}{|c|c|c|c|c|c|}
\hline Zareki-R & Observed Pre-NIMT & Classification & Observed Post-NIMT & Classification & Mean Expected \\
\hline Counting Dots & 2 & Mild & 2 & Mild & $3.5(0.8)$ \\
\hline Counting Backwards & 1 & Moderate & 2 & Mild & $3.2(1.2)$ \\
\hline Dictation of Numbers & 4 & Moderate & 6 & Average & $11.6(3.7)$ \\
\hline Mental Calculation & 0 & Severe & 5 & Severe & $25.1(11.8)$ \\
\hline Reading Numbers & 8 & Severe & 11 & Average & $13.3(3.3)$ \\
\hline Positioning Numbers & 5 & Severe & 4 & Severe & $15.6(5.0)$ \\
\hline Oral Comparison & 8 & Mild & 14 & Average & $12.1(3.8)$ \\
\hline Perceptive Estimation & 6 & Average & 4 & Average & $5.4(2.4)$ \\
\hline Contextual Estimation & 8 & Moderate & 14 & Average & $13.4(4.4)$ \\
\hline Problem Solving & 0 & Severe & 2 & Average & $5.5(3.8)$ \\
\hline Written Comparison & 6 & Severe & 16 & Average & $18.4(2.8)$ \\
\hline Memory of Digits & 18 & Average & 26 & Average & $23.9(8.3)$ \\
\hline Total & 48 & Severe & 80 & Moderate & $127.3(31.6)(31.6)$ \\
\hline
\end{tabular}

Note: Mild impairment (-1 SD); Moderate impairment (-2SD); Severe impairment (-3SD) according to normative data Santos et al. (2012).

production, except for mental calculation and positioning numbers, calculus and number line systems (Table 4). This single case reinforces the observations of beneficial effect of NIMT in Numerical Cognition. It shows that even a child with resistant low math achievement was able to improve in number production. Secondly, and less plausible is that perhaps some of the children from Cluster 2 should not be classified as DD, then rather than a persistent disorder, they would have a transitory Low Achievement (Lucangeli \& Mammarella, 2010) that is more responsive to interventions (Fuchs et al., 2013). In this case, the NIMT would suitable, up to some extent, for both children with LA and DD.

According to our findings, the NIMT showed to be functional for rehabilitation of children with Low Achievement in math for all Numerical Cognition system and on number production in children with DD. The activities performed in NIMT, such as mental rotation, transcription of sounds, and reading images to produce sounds (pseudo scores), seem to strengthen skills that mainly require symbol recognition. Furthermore, these findings corroborate with studies using instrumental musical training which have shown that short period training using musical principles could improve cognitive abilities (Rauscher \& Zupan, 2000), and particularly math (Schellenberg, 2006).

From a clinical point of view, these outcomes show the importance of early diagnosis of children with LA and DD to provide a satisfactory rehabilitation (Santos et al., 2012). Furthermore, although it is not explicitly stated in the ICD-10, the diagnostic criteria assume that learning difficulties should be evident over a period of time, which means that the follow up of the symptoms is essential (Mazzocco \& Räsänen, 2013). We consider that it is indispensable to follow up individual profiles since difficulties in math may modify across the time but remain disabling.

There is a lack of outcome studies currently available that demonstrate the efficacy of NIMT, specifically on Numerical Cognition. In the present study, all precautions related to experimental control were made to keep measures and outcomes reliable. In addition, the protocol had specific tasks to assess different abilities and screened for common comorbidities. Therefore, this paper was prepared as an effort to describe the basic structure of our NIMT program, and to expand knowledge about the techniques that are suitable for cognitive rehabilitation of numerical cognition in children with DD. We argue that NIMT achieved its goals with many advantages. It has low costs as it can be carried out at school, it is pleasant for participants and promotes inclusion, avoiding stigma. Moreover, NIMT does not require mobility on the part of parents or students and only demands that a qualified music teacher is trained to use the proposed methodologies (Ribeiro, 2013; Ribeiro \& Santos, 2015). Future studies may explore specific musical structures that can be used for rehabilitation in different types of learning disabilities in order to observe possible transfer effects and neuroplasticity. In sum, future research will be essential to explore long-term training and the differences between methodologies utilizing musical elements.

\subsection{Limitations}

In fact, all musical training studies quoted had an independent variable called control group, as a non-intervention group. However, clinical studies assessing the effects of interventions commonly included a clinical group and a non-clinical group performing the procedure, similar to our experimental design (Ashkenazi \& Henik, 2012; Kucian et al., 2011). At the same time, it would not be ethically suitable to delay or to deprive a clinical group of treatment. Although the present research did not include a non-intervention control group, the normative data study of the Zareki-R (Santos et al., 2012) was established with typically developing children from the same region and cultural background, which were not attending any training at the time of study. Thus, the data of the normative study functioned as a control (untrained) group to the present sample. Our findings represent preliminary evidence of the beneficial effects of NIMT on Numerical Cognition for both children with DD and with typical development. 


\section{Acknowledgments}

This work was supported by the Fundação de Amparo à Pesquisa do Estado de São Paulo (FAPESP) [grant number 11/01907-4]. We particularly thank the parents and children for their participation and the cooperation of the government schools at Assis city in São Paulo State.

\section{References}

Associação Brasileira de Empresas de Pesquisa. (2008). Critério de classificação econômica no Brasil.. Retrieved from. http://www.abep.org/codigosguias/ABEP_CCEB.pdf

Alloway, T. P., \& Passolunghi, M. C. (2011). The relationship between working memory, IQ and mathematical skills in children. Learning and Individual Differences, 21, 133-137. http://dx.doi.org/10.1016/j.lindif.2010.09.013

Alloway, T. P. (2006). Working memory and children with developmental coordination disorders. In T. P. Alloway, \& S. E. Gathercole (Eds.), Working memory and neurodevelopmental conditions (pp. 161-187). New York: Psychology Press

Alloway, T. P. (2007). Automated working memory assessment: translated and reproduced by permission of harcourt assessment. London: Harcourt Assessment

Angelini, A. L., Alves, I. C. B., Custódio, E. M., Duarte, W. F., \& Duarte, J. L. M. (1999). Matrizes progressivas coloridas de raven: Escala especial. São Paulo: entro Editor de Testes e Pesquisas em Psicologia.

Ashkenazi, S., \& Henik, A. (2012). Does attentional training improve numerical processing in developmental dyscalculia? Neuropsychology, 26(1), 45-56. http://dx.doi.org/10.1037/a0026209

Bastos, J. A., Cecato, A. M. T., Martins, M. R. I., Grecca, K. R. R., \& Pierini, R. (2016). The prevalence of developmental dyscalculia in Brazilian public school system. Arquivos de Neuro-Psiquiatria, 74(3), 201-206. http://dx.doi.org/10.1590/0004-282X20150212

Bengtsson, S. L., \& Ullén, F. (2006). Dissociation between melodic and rhythmic processing during piano performance from musical scores. Neuroimage, 30(1), 272-284. http://dx.doi.org/10.1016/j.neuroimage.2005.09.019

Bilharz, T. D., Bruhn, R. A., \& Olson, J. E. (2000). The effect of early music training on child cognitive development. Journal of Applied Developmental Psychology, 20, 615-636. http://dx.doi.org/10.1016/S0193-3973(99)00033-7

Butterworth, B. (2010). Foundational numerical capacities and the origins of dyscalculia. Trends in Cognitive Sciences, 14, 534-541. http://dx.doi.org/10.1016/j.tics.2010.09.007

Camargo, E. B. (2007). O Pensamento musical e a prática docente: As demandas da contemporaneidade no ensino da música. Master's thesis. São Paulo, Brazil: São Paulo University. Retrieved from. http://www.teses.usp.br/teses/disponiveis/48/48134/tde-17122009-112023/pt-br.php

Carmo, J. S., \& Figueiredo, R. M. E. (2005). Aprendizagem, emoção e ansiedade à matemática: indícios e vestígios de histórias de punição e fracasso no ensino da matemática. Trilhas - revista do Centro de Ciências Humanas e Educação, 7(15), 85-93.

Chaudhary, N., \& Sharma, B. (2012). Impact of employee motivation on performance (Productivity) in private organization. International Journal of Business Trends and Technology, 2(4)

Cheek, J., \& Smith, L. R. (1998). Music training and mathematics achievement of ninth graders. Adolescence, 34, 759-761. ERIC Document Reproduction Service No. ED 425918.

Cheng, Y., \& Mix, K. S. (2014). Spatial training improves children's mathematics ability. Journal of Cognition and Development, 15(1) http://dx.doi.org/10.1080/15248372.2012.725186

Cohen Kadosh, R., Dowker, A., Heine, A., Kaufmann, L., \& Kucian, K. (2013). Interventions for improving numerical abilities: Present and future. Trends in Neuroscience and Education, 2(2), 85-93. http://dx.doi.org/10.1016/j.tine.2013.04.001

Costa-Giomi, E. (1999). The effects of three years of piano instruction on children's cognitive development. Journal of Research in Music Education, 47, 198-212. http://dx.doi.org/10.2307/3345779

Cronbrach, L. J. (1951). Coefficient Alpha and the Internal Structure of Tests. Psychometrika, 16(8). Retrieved from. htt://kttm.hoasen.edu.vn/sites/default/files/2011/12/22/cronbach_1951_coefficient_alha.df

Cunha, J. A., Trentini, C. M., Argimon, I. L., Oliveira, M. S., Werlang, B. G., \& Prieb, R. G. (2005). Adapatação e padronização brasileira do teste Wisconsin de classificação de cartas (1a ed)). São Paulo: Casa do Psicólogo.

Davis, M. A. (2000). Learning. ... the beat goes on. Childhood Education, 76, 148-154. http://dx.doi.org/10.1080/00094056.2000.10522096

Desmet, C., Imbo, I., De Brauwer, J., Brass, M., Fias, W., \& Notebaert, W. (2012). Error adaptation in mental arithmetic. Quarterly Journal of Experimental Psychology, 65, 1059-1067. http://dx.doi.org/10.1080/17470218.2011.648943

Esteki, M. (2013). Effectiveness of Music Training on reorganization of brain and poor intellectual abilities in female students with dyscalculia (7-9 years old). Global Journal of Arts Education, 3, 06-10. Retrieved from URL. http://www.world-education-center.org/index.php/gjae/article/viewArticle/2836

Forgeard, M., Winner, E., Norton, A., \& Schlaug, G. (2008). Practicing a Musical Instrument in Childhood is Associated with Enhanced Verbal Ability and Nonverbal Reasoning. PLoS One, 3(10), e3566. http://dx.doi.org/10.1371/journal.pone.0003566

Fuchs, L. S., Geary, D. C., Compton, D. L., Fuchs, D., Schatschneider, C., Hamlett, C. L., \& Changas, P. (2013). Effects of first-grade number knowledge tutoring with contrasting forms of practice. Journal of Educational Psychology, 105(1), 58-77. http://dx.doi.org/10.1037/a0030127

Gentner, D. (2001). Spatial metaphors in temporal reasoning. In M. Gattis (Ed.), Spatial schemas in abstract thought (pp. 203-222). Cambridge, MA: MIT Press.

Goulart, D. (2000). Dalcroze, Orff, Suzuki e Kodály: Semelhanças, diferenças, especificidades. Rio de Janeiro, RJ: Conservatório Brasileiro de Música do Rio de Janeiro.

Grandin, T., Shaw, G., \& Peterson, M. (1998). Spatial-Temporal versus Language-Analytic Reasoning: The Role of Music Training. Arts Education Policy Review, 99(6), 11-14. http://dx.doi.org/10.1080/10632919809599481

Graziano, A. B., Peterson, M., \& Shaw, G. L. (1999). Enhanced learning of proportional math through music training and spatial- temporal training. Neurological Research, 21, 139-152. http://dx.doi.org/10.1080/01616412.1999.11740910

Gross-Tsur, V., Manor, O., \& Shalev, R. S. (1996). Developmental dyscalculia: Prevalence and demographic features. Developmental Medicine and Child Neurology, 38, 25-33. http://dx.doi.org/10.1111/j.1469-8749.1996.tb15029.x

Hannon, E. E., \& Trainor, L. J. (2007). Music acquisition: Effects of enculturation and formal training on development. Trends in Cognitive Psychology, 11(11), 466-472. http://dx.doi.org/10.1016/j.tics.2007.08.008

Heaton, K. R., Chelune, G. J., Talley, J. L., Kay, G. G., Curtiss, G., \& Cunha, J. A. (2005). Manual do teste Wisconsin de Classificação de Cartas. Revisado e Ampliado. São Paulo, Casa do Psicólogo: Adaptação e Padronização Brasileira, Jurema Alcides Cunha e Cols.

Herholz, S. C., \& Zatorre, R. J. (2012). Musical training as a framework for brain plasticity: Behavior, function, and structure. Neuron, 76(3), 486-502. http://dx.doi.org/10.1016/j.neuron.2012.10.011

Kaufmann, L., \& von Aster, M. (2012). The diagnosis and management of Dyscalculia. Deutsches Ärzteblatt International, 109(45), 767-778. http://dx.doi.org/10.3238/arztebl.2012.0767

Kaufmann, L., Mazzocco, M. M., Dowker, A., Von Aster, M., Göbel, S. M., Grabner, R. H., et al. (2013). Dyscalculia from a developmental and differential perspective. Frontiers in Psychology, 4, 516. http://dx.doi.org/10.3389/fpsyg.2013.00516

Klingberg, T. (2010). Training and plasticity of working memory. Trends in Cognitive Sciences, 14, 317-324. http://dx.doi.org/10.1016/j.tics.2010.05.002 
Kranz, C. R., \& Healy, L. (2013). Pesquisas sobre discalculia no Brasil: Uma reflexão a partir da perspectiva histórico-cultural. REMATEC. Revista de Matemática, Ensino e Cultura (UFRN), 8, 58-81. Retrieved from:.

http://www.matematicainclusiva.net.br/pdf/PESQUISAS\%20SOBRE\%20DISCALCULIA\%20NO\%20BRASIL.pdf

Kucian, K., Grond, U., Rotzer, S., Henzi, B., Schönmann, C., Plangger, et al. (2011). Mental number line training in children with developmental dyscalculia. Neuroimage, 57, 782-795. http://dx. doi.org/10.1016/j.neuroimage.2011.01.070

Landerl, K., Bevan, A., \& Butterworth, B. (2004). Developmental dyscalculia and basic numerical capacities: A study of 8-9-year-old students. Cognition, 93, 99-125. http://dx.doi.org/10.1016/j.cognition.2003.11.004

Landerl, K. (2013). Development of numerical processing in children with typical and dyscalculic arithmetic skills-a longitudinal study. Frontiers in Psychology, 4, 459. http://dx.doi.org/10.3389/fpsyg.2013.00459

Lucangeli, D., \& Mammarella, I. (2010). Psicologia della cognizione numerica: Approcci teorici, valutazione e intervento (Numerical knowledge psychology: Theory, assessment and intervention). Milan, Italy: Franco Angeli.

Mazzocco, M. M. M., \& Räsänen, P. (2013). Contributions of longitudinal studies to evolving definitions and knowledge of developmental dyscalculia. Trends in Neuroscience and Education, 2, 65-73. http://dx.doi.org/10.1016/j.tine.2013.05.001

McCloskey, M., Caramazza, A., \& Basili, A. (1985). Cognitive mechanisms in number processing and calculation: Evidence from dyscalculia. Brain and Cognitive, 4, 171-196. http://dx.doi.org/10.1016/0278-2626(85)90069-7

Miendlarzewska, E. A., \& Trost, W. J. (2013). How musical training affects cognitive development: Rhythm, reward and other modulating variables. Frontiers in Neuroscience, 7, 279. http://dx.doi.org/10.3389/fnins.2013.00279

Moeller, K., Fischer, U., Nuerk, H.-C., \& Cress, U. (2015). Computers in mathematics education-Training the mental number line. Computers in Human Behavior, 48, 597-607. http://dx.doi.org/10.1016/j.chb.2015.01.048

Moreno, S., Bialystok, E., Barac, R., Schellenberg, E. G., Cepeda, N. J., \& Chau, T. (2011). Short-term music training enhances verbal intelligence and executive function. Psychological Science, 22(11), 1425-1433. http://dx.doi.org/10.1177/0956797611416999

Murphy, M. M., Mazzocco, M. M. M., Hanich, L. B., \& Early, M. C. (2007). Cognitive characteristics of children with mathematics learning disability (MLD) vary as a function of the cutoff criterion used to define MLD. Journal of Learning Disabilities, 40, 458-478. http://dx.doi.org/10.1177/00222194070400050901

Nutley, S. B., Darki, F., \& Klingberg, T. (2013). Music practice is associated with development of working memory during childhood and adolescence. Frontiers in Human Neuroscience, 7, 926, 10.3389/fnhum.2013.00926.

Peretz, I., \& Kolinsky, R. (1993). Boundaries of separability between melody and rhythm in music discrimination: A neuropsychological perspective. The Quarterly Journal of Experimental Psychology Section A, 46(2), 301-325. http://dx.doi.org/10.1080/14640749308401048

Praet, M., \& Desoete, A. (2014). Enhancing young children's arithmetic skills through nonintensive, computerised kindergarten interventions: A randomised controlled study. Teaching and Teacher Education, 39, 56-65. http://dx.doi.org/10.1016/j.tate.2013.12.003

Proverbio, A. M., Calbi, M., Manfredi, M., \& Zani, A. (2014). Audio-visuomotor processing in the Musician's brain: An ERP study on professional violinists and clarinetists. Scientific Reports, 5866. http://dx.doi.org/10.1038/srep05866

Rauscher, F. H., \& Shaw, G. L. (1998). Key components of the mozart effect. Perceptual and Motor Skills, 86, 835-841. http://dx.doi.org/10.2466/pms.1998.86.3.835

Rauscher, F. H., \& Zupan, M. A. (2000). Classroom keyboard instruction improves kindergarten children's spatial-temporal performance: A field experiment. Early Childhood Research Quarterly, 15, 215-228. http://dx.doi.org/10.1016/S0885 2006(00)00050-8

Rauscher, F. H., Shaw, G. L., Levine, L. J., Wright, E. L., Dennis, W. R., \& Newcomb, R. L. (1997). Music training causes long-term enhancement of preschool children's spatial-temporal reasoning abilities. Neurological Research, 19, 2-8. Retrieved from URL. http://faculty.washington.edu/demorest/rauscher.pdf

Re, A. M., Pedron, M., Tressoldi, P. E., \& Lucangeli, D. (2014). Response to specific training for students with different levels of mathematical difficulties. Exceptional Children, 80, 337-352. http://dx.doi.org/10.1177/0014402914522424. Retrieved from URL

Ribeiro, F. S., \& Santos, F. H. (2012). Treino Musical e Capacidade da Memória Operacional em Crianças Iniciantes, Veteranas e Sem Conhecimentos Musicais. Psicologia: Reflexão e Crítica, 25, 400-408. http://dx.doi.org/10.1590/S0102-79722012000300016

Ribeiro, F. S., \& Santos, F. H. (2015). Métodos específicos para impulsionar a memória operacional. In F. H. Santos, V. M. Andrade, \& O. F. A. Bueno (Eds.), Neuropsicologia hoje (pp. 299-306). Artmed: São Paulo.

Ribeiro, F. S., Tonoli, M. C., \& Santos, F. H. (2016). Non-Instrumental Musical Training in Children with Developmental Dyscalculia: Effects on Working Memory Capacity and Numerical Cognition Systems Frontiers. , in press.

Ribeiro, F. S. (2013). O efeito do treino musical sobre a capacidade da memória operacional e da cognição numérica de crianças com discalculia do desenvolvimento. Master's thesis. Bauru, Brazil: Universidade Estadual Paulista - Júlio de Mesquista Filho. Retrieved from. http://hdl.handle.net/11449/97434

Rotzer, S., Loenneker, T., Kucian, K., Martin, E., Klaver, P., \& von Aster, M. (2009). Dysfunctional neural network of spatial working memory contributes to developmental dyscalculia. Neuropsychologia, 47, 2859-2865. http://dx.doi.org/10.1016/j.neuropsychologia.2009.06.009

Rubinsten, O., \& Tannock, R. (2010). Mathematics anxiety in children with developmental dyscalculia. Behavioral and Brain Functions, $6,46$. http://dx.doi.org/10.1186/1744-9081-6-46

Santos, F. H., Silva, P. A., Ribeiro, F. S., Dias, A. L. R. P., Frigério, M. C., Dellatolas, G., et al. (2012). Number processing and calculation in Brazilian children aged 7-12 years. Spanish Journal of Psychology, 15, 513-525. http://dx.doi.org/10.5209/rev_SJOP.2012.v15. n2.38862

Santos, F. H. (2002). Memória operacional de crianças normais e com lesões congênitas: Desenvolvimento cognitivo e reorganização cerebral. São Paulo, Brazil: Universidade Federal de São Paulo-Escola Paulista de Medicina.

Schellenberg, E. G. (2006). Long-term positive associations between music lessons and IQ. Journal of Educational Psychology, $98,457-468$. http://dx.doi.org/10.1037/0022-0663.98.2.457

Schmithorst, V. J., \& Holland, S. K. (2004). The effect of musical training on the neural correlates of math processing: A functional magnetic resonance imaging study in humans. Neuroscience Letters, 354(3), 193-196. http://dx.doi.org/10.1016/j.neulet.2003.10.037

Schuchardt, K., Kunze, J., Grube, D., \& Hasselhorn, M. (2006). Arbeitsgedächtnisdefizite bei Kindern mit schwachen Rechen- und Schriftsprachleistungen. Zeitschrift für Pädagogische Psychologie, 20, 261-268. http://dx.doi.org/10.1024/1010-0652.20.4.261

Shadish, W. R., Cook, T. D., \& Campbell, D. T. (2002). Experimental and quasiexperimental designs for generalized causal inference. Belmont, CA: Wadsworth Cengage Learning.

Shalev, R. S., Manor, O., Auerbach, J., \& Gross-Tsur, V. (1998). Persistence of developmental dyscalculia: What counts? Results from a three-year prospective follow-up study. Journal of Pediatrics, 133, 358-362. http://dx.doi.org/10.1016/S0022-3476(98)70269-0

Shalev, R. S., Manor, O., \& Gross-Tsur, V. (2005). Developmental dyscalculia: A prospective six-year follow-up. Developmental Medicine and Child Neurology, 47, 121-125. http://dx.doi.org/10.1017/S0012162205000216

Silva, P. A., \& Santos, F. H. (2011). Discalculia do desenvolvimento: Avaliação da representação numérica pela ZAREKI-R. Psicologia: Teoria e Pesquisa, 27(2), 169-177. http://dx.doi.org/10.1590/S0102-37722011000200003

Stein, L. M. (1994). TDE-minus Teste de desempenho escolar. São Paulo: Casa do psicólogo.

Thornton, T. (2013). A comparison of state assessment scores between music and nonmusic students. Applications of Research in Music Education, 32, 5-11. http://dx.doi.org/10.1177/8755123313502339

Von Aster, M. G., \& Dellatolas, G. (2006). ZAREKI-R: Batterie pour l'évaluation du traitement des nombres et du calcul chez l'enfant. Adaptation francaise. Paris: ECPA.

Von Aster, M. G., \& Shalev, R. S. (2007). Number development and developmental dyscalculia. Developmental Medicine E' Child Neurology, 49, 868-873. http://dx.doi.org/10.1111/j.1469-8749.2007.00868.x 
World Health Organization (WHO). (2004). International statistical classification of diseases and related health problems. Porto Alegre: Artes Médicas. Warren, J. D. (1999). Variations on the musical brain. Journal of the Royal Society of Medicine, 92, 571-575. Retrieved from:. http://www.brainmusic.org/EducationalActivities/Warren_musicalbrain1999.pdf

Wenger, W., \& Wenger, S. H. (1990). Training music sight-reading and perfect pitch in young children, as a way to enhance their intelligence. Journal of the Society for Accelerative Learning and Teaching, 15, 77-89. Retrieved from:. http://files.eric.ed.gov/fulltext/ED347789.pdf

Willis, C. G. (2016). Impact of music education on mathematics achievement scores among middle school students (Doctoral dissertation).. Retrieved from. http://scholarworks.waldenu.edu/dissertations

Wilson, A. J., \& Dehaene, S. (2007). Number sense and developmental dyscalculia. In D. Coch, G. Dawson, \& K. Fischer (Eds.), Human behavior, learning and the developing brain: A typical development. New York: Guilford Press.

Yang, H., Lu, J., Gong, D., \& Yao, D. (2016). How do musical tonality and experience affect visual working memory? Neuroreport, 27(2), 94-98. http://dx.doi.org/10.1097/WNR.0000000000000503

Zuk, J., Benjamin, C., Kenyon, A., \& Gaab, N. (2014). Behavioral and neural correlates of executive functioning in musicians and non-musicians. Public Library Of Science, 9(6), e99868. http://dx.doi.org/10.1371/journal.pone.0099868 